\title{
HIGHLY SENSITIVE TIMER-BASED RESISTANCE DEVIATION TO TIME CONVERTER
}

\author{
Zeeshan S., Nadratul A.G., Noor Amalina R., Sumayyah D., Rumana T., \\ MYO M.O., AND SHEROZ K. \\ Electrical and Computer Engineering Department, Faculty of Engineering, \\ International Islamic University Malaysia, Jalan Gombak, \\ 53100 Kuala Lumpur, Malaysia. \\ zeesh_87@hotmail.com,sheroz@iium.edu.my
}

\begin{abstract}
Based on an inexpensive popular precision timing chip 555 timer, a resistance to time converter is proposed in this paper it is indeed capable of converting resistive and capacitive changes into pulse widths of proportional durations. This converter exhibits a compatibility of wider conversion range with a reasonable level of sensitivity required for industrial applications. The circuit is expected to have application in oil and water supply schemes. Simulated results are shown to be compared with mathematical derivations, both reporting a good level of response matching very closely with the derived results, where a $70 \%$ deviation of an elemental value corresponds to a mismatch of 50-70 micro-seconds between derived and simulation results.
\end{abstract}

ABSTRAK: Rintangan kepada penukar masa berdasarkan cip pemasaan tepat dan murah yang popular 555, telah dicadangkan dalam kertas kerja ini. Ia memang mampu menukarkan perubahan perintang dan pemuat kepada lebar nadi jangka masa berkadar. Penukar ini mempamerkan keserasian pelbagai penukaran yang lebih luas dengan tahap sensitiviti yang munasabah untuk aplikasi perindustrian. Litar ini dijangka mempunyai applikasi dalam skim bekalan minyak dan air. Keputusan simulasi dibandingkan dengan terbitan matematik, kedua-duanya menunjukkan keputusan yang sangat rapat, di mana 70\% daripada nilai asas berkaitan dengan tidak sepadan 50-70 mikro-saat antara keputusan simulation dan terbitan matematik.

KEYWORDS: resistance to pulse converters; linearity; sensitivity; resistance to frequency converters

\section{INTRODUCTION}

In monitoring, automation and control, small resistive changes can emmulate the physical parameter of our interest such as force, displacement, vibration, and temperature. Conversion of resistive changes into corresponding time period or frequency changes has been presented since very long. Such conversions have been one of the most reliable and significant measurement steps in resistive transducers applications commonly used in today's industry. Their application is on the rise particularly in cases of automation and control being carried out wirelessly through small distances such as narrow gaps.

Resistance to time (or frequency) converters of critical importance in small measurements activities. These measurements have been traditionally carried out by transducers normally exhibiting linear precise responses over a limited range. When carried out over a wide range, such transducers usually start showing nonlinear responses, which results in inaccuracies. Such inaccuracies were not considered noticeable when 
Zeeshan et al.

looked from the traditional transducers' view point, where even sizeable errors were overlooked. However, in today's smart applications the overlooked ignorable mismatches are considered unaffordable. Therefore, it is crucial to implement a circuit which would be able to produce a linear as well as highly sensitive output.

Various papers have presented and proposed converter circuit that can be implemented in the transducer to produce a linear as well as highly sensitive output. Two main papers of interest are [1-2] which presented the circuit by implementing Wheatstone bridge as well as amplifier bridge. In these papers, the effect of offset error and its compensation is being discussed to show that linearity improves with offset compensation scheme.

The first paper by Mochizuki and Watanabe [1] implemented a relaxation oscillator with the combination of the Wheatstone bridge resistor. Wheatstone is implemented due to its ability to detect small changes in terms of resistance deviations as compared to the early implementation of relaxation oscillator [1]. However, nonlinearity characteristic starts to appear when the period is amplified due to time-delay which is onward solved by using compensation techniques.

The second paper by S. Kaliyugavaradan [2] proposed a refined version of the circuit which not only rules out the need for using compensation arrangement, but also provided grounded transducer.

This paper refines the existing works with by implementing a monostable circuit to produce the same resistance deviation to frequency converter with improved linearity and sensitivity over a wider range. This paper will attempt to prove the reliability of using monostable circuit by presenting the results of the output as compared to the theoretical derivations.

\section{STATE OF THE ART WORK}

Making use of a bridge, reference [1] suggests a resistance to frequency converter with a resolution of $0.05 \%$ and linearity maintained over a given range. The offset error produced by the OP AMP used is a major obstacle, which is addressed by the feedback of a fraction of the output. The suggested circuit has signal processing applications.

A linear resistance-to-time converter with high resolution has been reported [2]. The results obtained had a good level of linearity with the nonlinearity error less than $\pm 0.1 \%$ over the range of $950 \Omega-2950 \Omega$ and the conversion sensitivity of $50 \mu \mathrm{s} / \Omega$.

Another highly quoted paper [3], proposes a resistance-to-time converter which is also implemented on a resistive bridge configuration. Over a resistance deviation range of $0-2$ $\Omega$, the converter exhibits a response with nonlinearity error less than $0.005 \%$. Further, it is reported to have exhibited a conversion sensitivity of $2832.4 \mu \mathrm{s} / \Omega$.

All the above converters are suggesting custom built electronic approaches, which on occasions will be making it challenging task, considering the availability of the required components. This converter uses a 555-timer connected in a monostable mode. This circuit produce small resistance variations as pulse-width conversions through the use of a 555-timer, that can be made easily available avoiding the requirement of custom-built electronic conversion circuit. The challenges are to obtain a high level of linearity and better conversion sensitivity over a wider range of resistance deviation. 
Zeeshan et al.

\section{THEORY AND SIMULATION OF PROPOSED RESISTANCE TO TIME CONVERTER}

The circuit diagram of Fig. 1(a) is a basic mono-stable multi-vibrator, also called 'one-shot' pulse generation circuit which uses a 555 IC timer circuit. The external resistor and capacitor (RC) network is connected between power supply and ground. An input trigger pulse is applied to trigger input pin (Pin4) of the timer which is normally kept at high. The output of the mono-stable multi-vibrator remains at low before it is triggered. As the trigger pin turns low the timer generate a pulse at the output for a period which is equal to the value of its time constant (values of external resistor and capacitor used). The duration of the resulting pulse can be theoretically derived as given in following equation.

$$
T=1.17 R C
$$

(a)

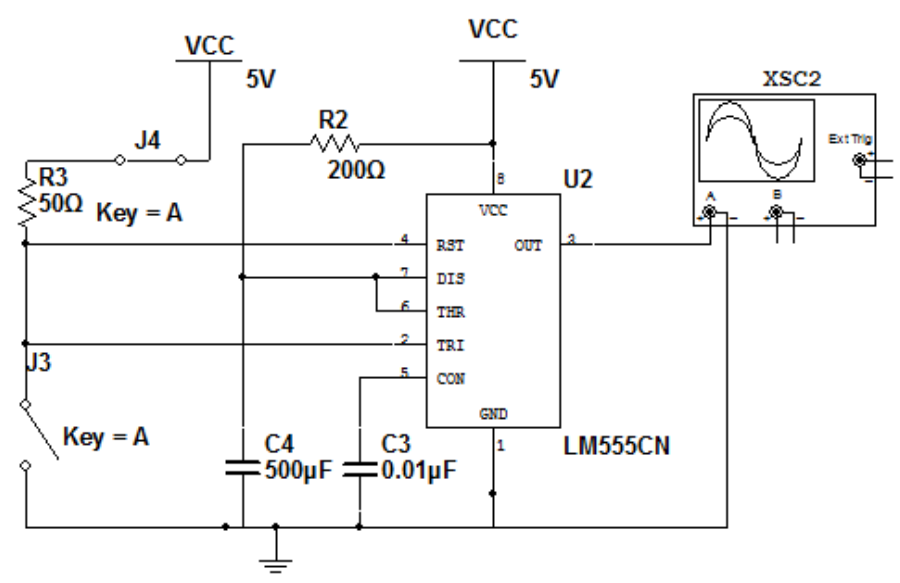

(b)

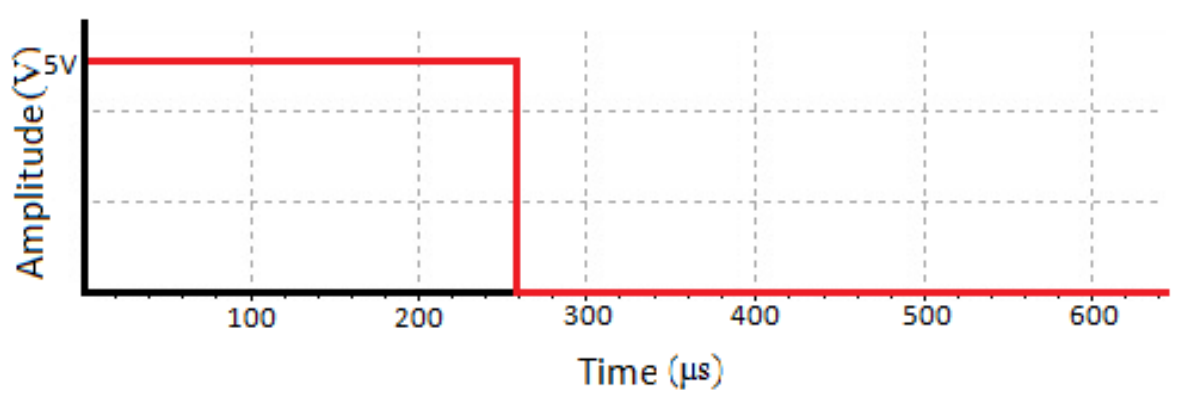

Fig. 1: (a) 555-Timer Based Monostable Pulse Generator (b) Output Pulse of 555-Timer Based Monostable Pulse Generator.

In another configuration Fig. 2 (a), two mono-stable circuits are used and connected in parallel. The same values are used for the external resistor and capacitor, having equal time constants, and as shown in Fig. 2(b), no pulse is produced as a result. 
IIUM Engineering Journal, Vol. 12, No. 6, 2011: Special Issue in Science and Ethics

Zeeshan et al.

(a)

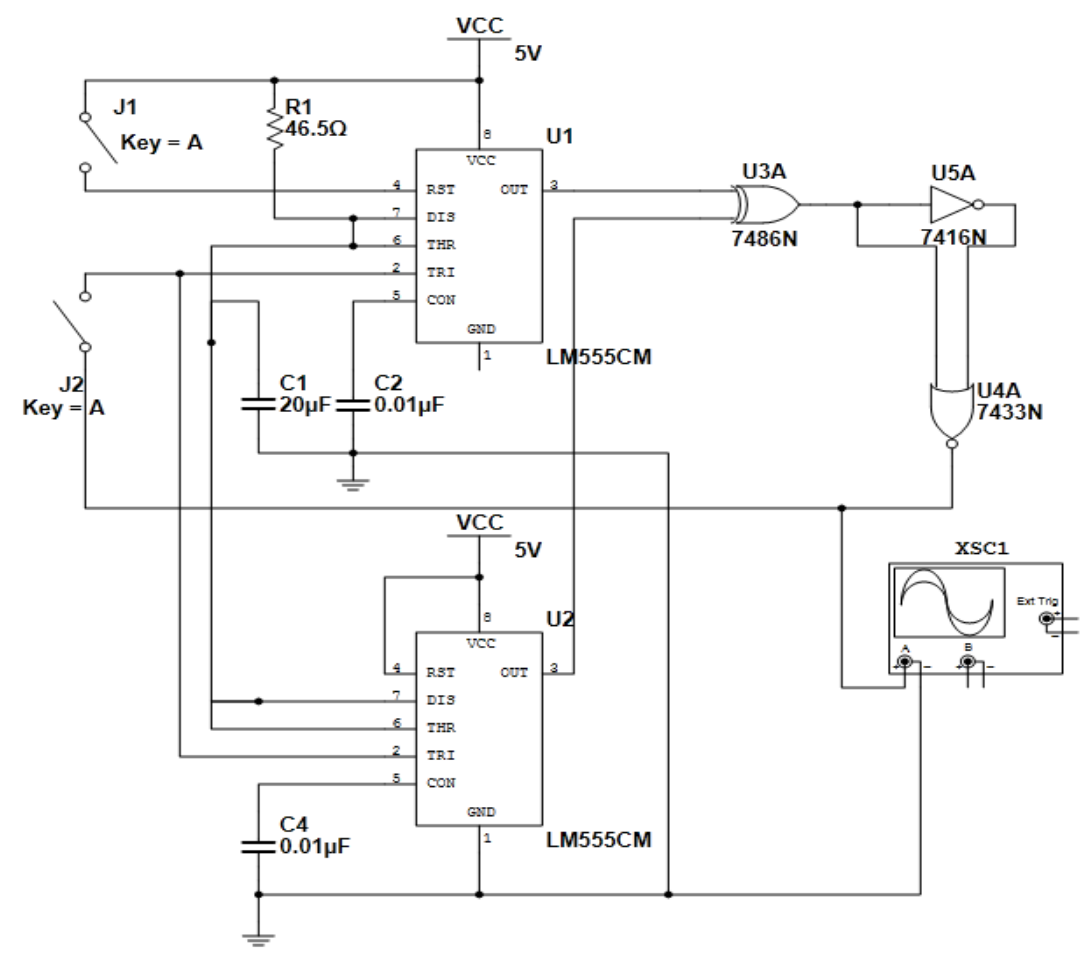

(b)

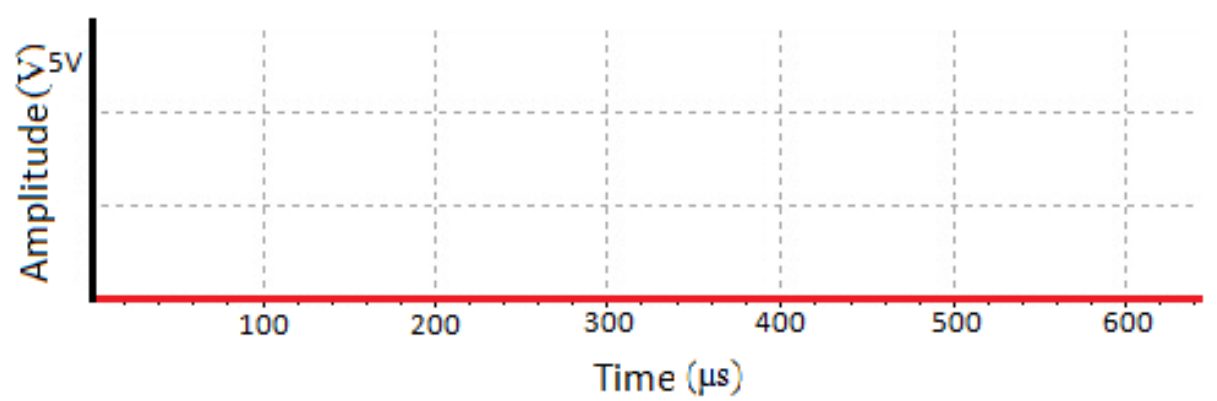

Fig. 2: (a) Two mono-stable circuits connected in parallel, (b) No pulse generated.

In another such configuration Fig. 3 (a), the two mono-stable circuits are connected in parallel similar to that shown in Fig. 2. Keeping capacitance the same, the resistance values are kept different for two unequal time constants. So, they do produce a pulse at the output of the exclusive-OR gate with width given by

$$
T=1.17\left(R_{2}-R_{1}\right) C
$$

(a) 


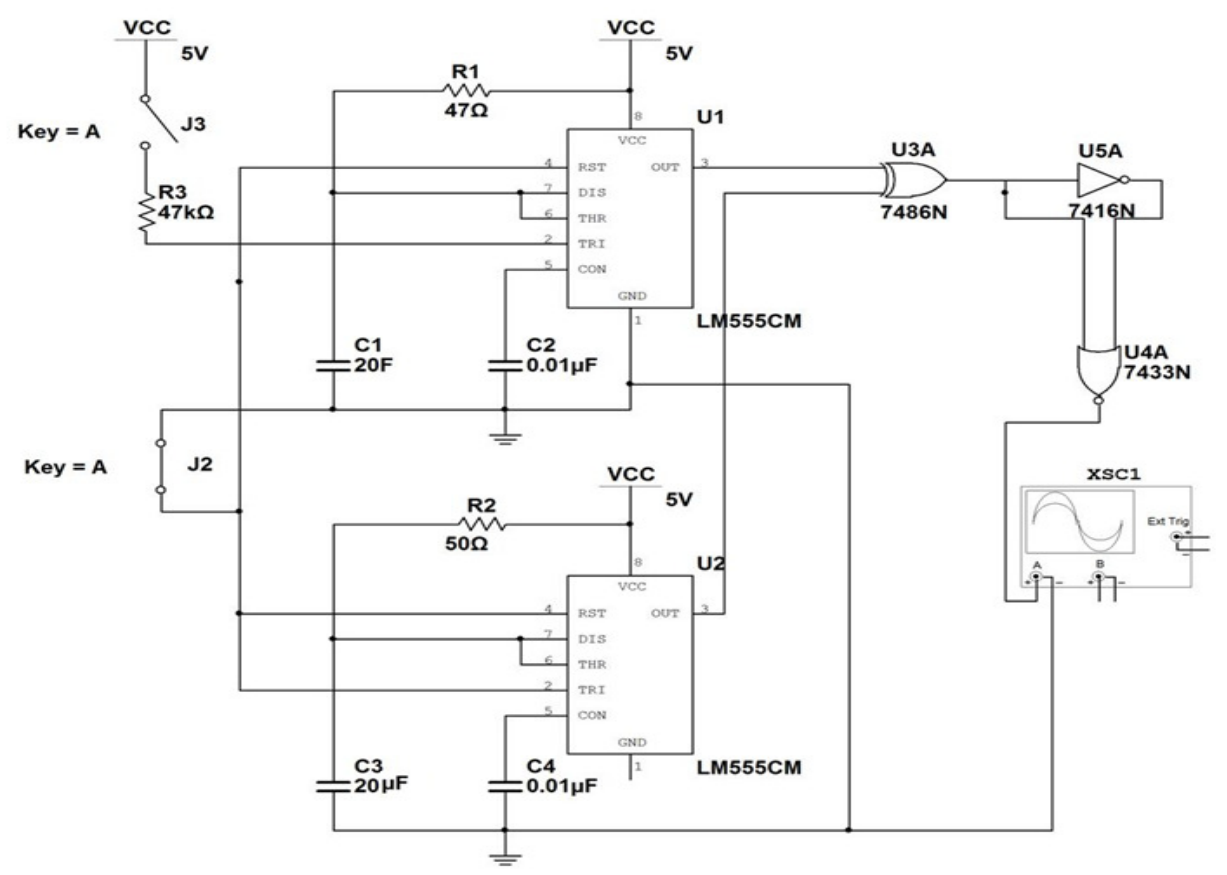

(b)

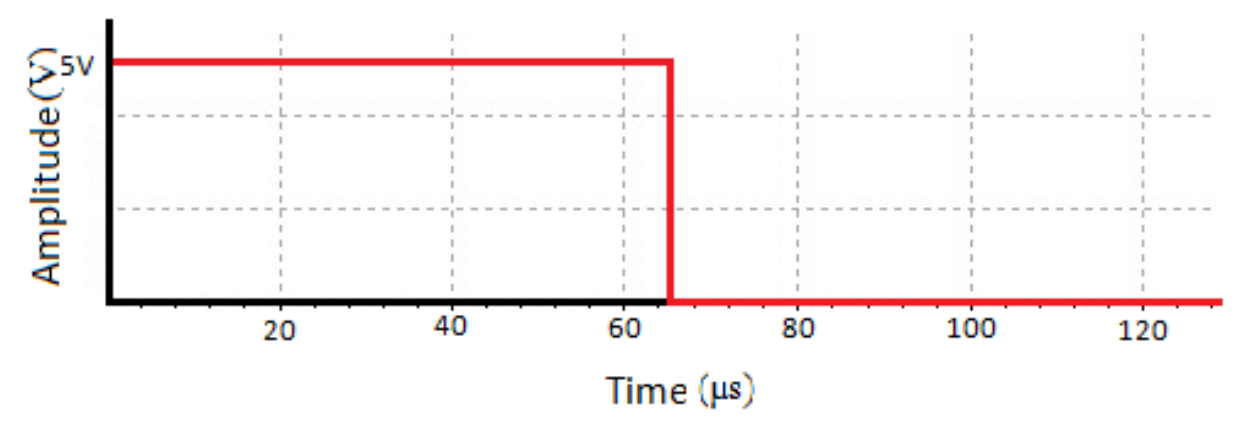

Fig. 3:(a) Two mono-stable circuits connected in parallel for resistive deviations (b) Generated output pulse of two mono-stable circuits connected in parallel with resistive deviations $(3 \Omega)$.

The final arrangement is presented in Fig. 4(a). Unlike the circuit of Fig. 3, in this circuit each mono-stable circuit has used resistors of equal values while two capacitors of dissimilar values. Ultimately this slightly modified arrangement attempts to produce pulse of a width given by

$$
\mathrm{T}=1.17 \mathrm{R}(\mathrm{C} 2-\mathrm{C} 1)
$$


(a)

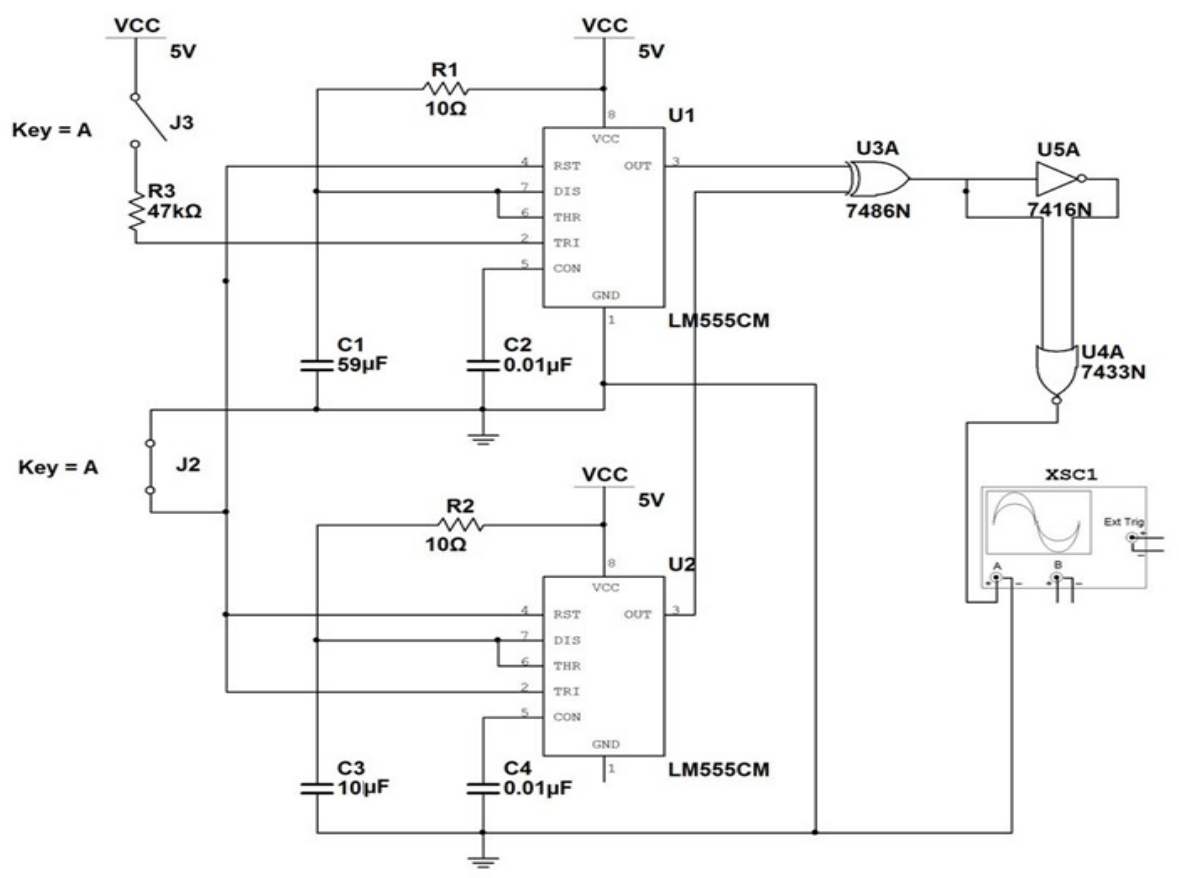

(b)

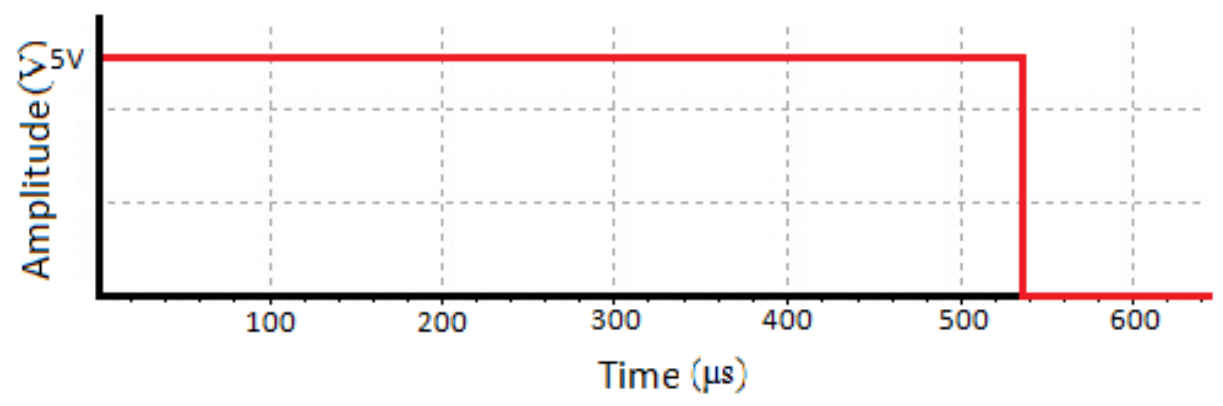

Fig. 4: (a). Two mono-stable circuits connected in parallel for capacitive deviation (b). Generated pulse of two mono-stable circuits connected in parallel for capacitive deviation $(49 \mu \mathrm{F})$.

\section{SIMULATION RESULTS AND DISCUSSION}

The proposed circuit has highlighted the conversion of a small resistance changes into narrow pulse widths (microsecond range). The relationship between these changes appears to be linear over a certain range of resistive and capacitive variations. In Figure 5(a) Pulsewidth versus percentage resistance deviation and while in Figure 5(b) Pulse-width versus Percentage capacitive deviations are shown respectively. These plots are derived from data given in Table 1 and 2 respectively (see APPENDIX I). The simulation plots generated using MATLAB confirm with the mathamatical equations. 


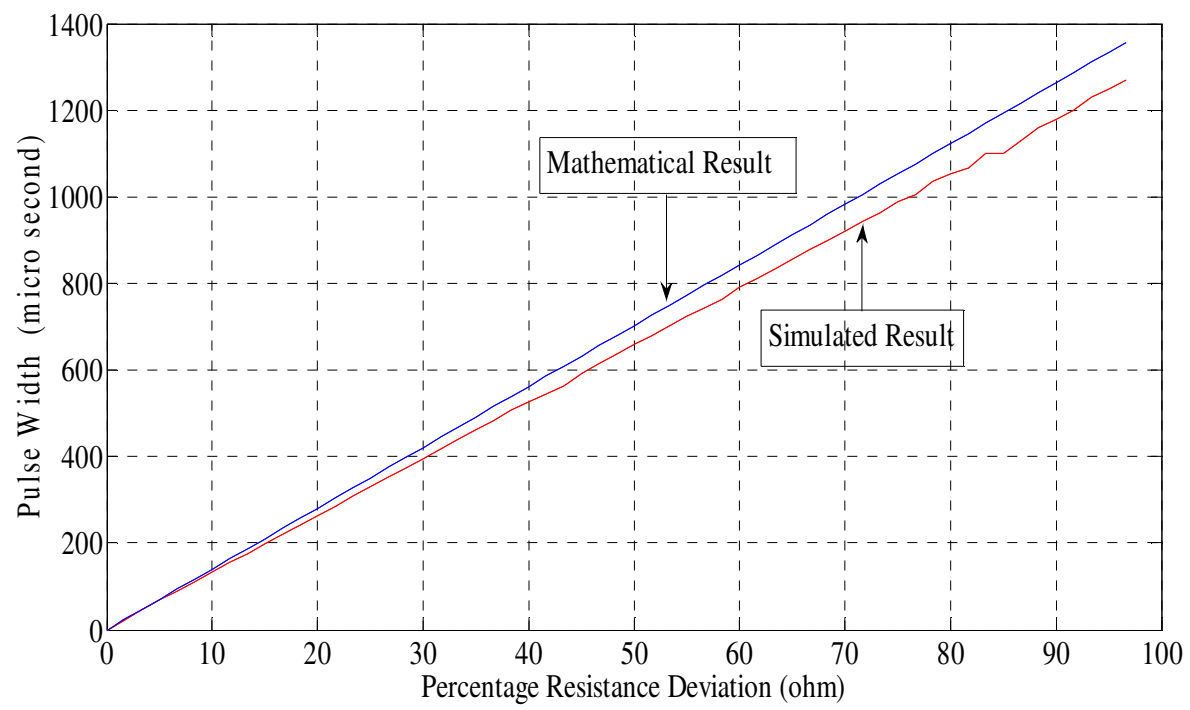

Fig. 5: (a) Pulse width versus percentage resistance deviation (in $\Omega$ ).

For resistance changes of up to $10 \Omega$, a pulse width of $200 \mu$ s is produced. The maximum width of pulse is about $1400 \mu$ s when the resistance deviation is near to about $100 \%$. sensitivity of $20 \mu \mathrm{s} / \Omega$ is obtained over this resistive deviation. It is apparent that the converter's sensitivity is of a poorer value than [8] but has shown a good level of linearity over a much wider range of 0-60 $\Omega(0-100 \%)$. Further increase of resistive values shows a nonlinear response.

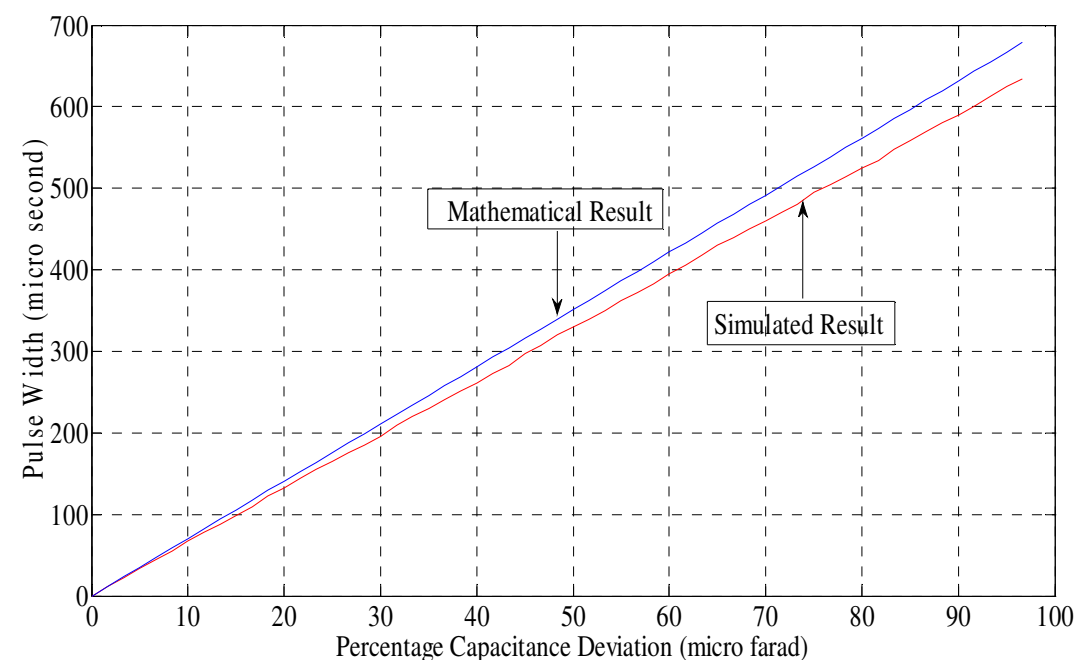

Fig. 5 (b): Pulse width versus Percentage capacitive deviation $(\mu \mathrm{F})$

Comparing the response shown Fig. 5(b), the conversion of pulse width with percentage increase in capacitive changes shows a direct linear behavior over the ranges 0 $90 \mu \mathrm{F}$ range. A variation of $100 \mu$ s pulse width is generated for a cpacitve chnage of $10 \mu \mathrm{F}$, giving a sensitivity of $10 \mu \mathrm{s} / \mu \mathrm{F}$ is obtained over the described range of $0-90 \mu \mathrm{F}$. 
Zeeshan et al.

From the resulting plots given above it is obvious that the size of the pulse width obtained is dependent on resistance and capacitance values respectively. Although this conversion of resistive and capacitive changes do not produce subsequent time width of same size, both the suggested circuits behaved in a linear fashion over a time under consideration. The results of this work can be applied in converting small resistive or capacitive changes into their pulses of width equivalent to corresponding changes. The same concepts might be useful for signal extract from embedded transducers as such concepts is the foundation principal of pulse-width-modulation (PWM). Further, the resolution and sensitivity of the circuits under consideration could be adjusted to application specific case study requirements.

\section{CONCLUSION}

A new design of resistance deviation to frequency converter utilizing a monostable circuit 555-timer is presented in this paper. From the simulation results, it is evident that the proposed converter circuit produce a good level of linearity of up to $100 \%$ ranges with sensitivity of $20 \mu \mathrm{s} / \Omega$ and $10 \mu \mathrm{s} / \mu \mathrm{F}$ for resistance and capacitance variations respectively. Unlike conventional circuits, this converter avoids using integrator, oscillator and bridge circuits. This simple converter is tolerent to offers better performance in terms of linearity and wider rage of daviations and is suitable for applications in the oil and water treatment industry

\section{REFERENCES}

[1] Kouji Mochizuki and Kenzo Watanabe, "A High-Resolution, Linear Resistance-toFrequency Converter," IEEE Transactions on Instrumentation and Measurement, vol. 45, no. 3, June 1996

[2] S. Kaliyugavaradan, "A Linear Resistance-To-Time Converter with High Resolution," IEEE Transactions on Instrumentation and Measurement, vol. 49, no. 1, February 2000

[3] W. S- Chung, M. Y- An, and S. H- Son, "A Simple Resistance-to-Time Converter for Resistive Sensors," ICICE Electronics Express, Vol. 5, No. 9, 310-315, May 2008

[4] V. Ferrari, D. Marioli, and A. Taroni, "Oscillator-based interface for measurand-plustemperature readout from resistive bridge sensors," IEEE Trans. Instrum. Meas., vol. 49, no. 3, pp. 585-590, Jun. 2000.

[5] Zvezditza P. Nenova and Toshko G. Nenov, Member, IEEE, "Linearization Circuit of the Thermistor Connection," IEEE Transactions on Instrumentation and Measurement, vol. 58, no. 2, February 2009

[6] Santiago Lizón-Martínez, Bernardo Tellini, Member, IEEE, Romano Giannetti, Senior Member, IEEE, and Guillermo Robles, Member, IEEE, "Measurement of Asymmetric Minor Loops in Soft Ferrites Up to Medium Frequencies," IEEE Transactions on Instrumentation and Measurement, vol. 58, no. 2, February 2009

[7] Hoon Kim, Won-Sup Chung, Hee-Jun Kim, Senior Member, IEEE, and Sang-Hee Son, "A Resistance Deviation-to-Pulsewidth Converter for Resistive Sensors," IEEE Transactions on Instrumentation and Measurement, vol. 58, no. 2, February 2009

[8] Ferran Reverter, Manel Gasulla and Ramon Pall as-Areny, "Analysis of interference effects on period-to-digital conversions," Institute of Physics Publishing Measurement Science and Technology, Meas. Sci. Technol. 16 (2005) 2261-2264 
IIUM Engineering Journal, Vol. 12, No. 6, 2011: Special Issue in Science and Ethics

Zeeshan et al.

\section{APPENDIX I}

Table 1

\begin{tabular}{|c|c|c|c|c|c|c|c|}
\hline S.No & $\begin{array}{l}\mathbf{R}_{\mathbf{1}} \\
(\mathbf{\Omega})\end{array}$ & $\begin{array}{l}\mathbf{R}_{\mathbf{2}} \\
(\mathbf{\Omega})\end{array}$ & $\begin{array}{c}\text { Change in } \\
R(\Omega)\end{array}$ & $\begin{array}{c}C \\
(\mu \mathbf{F})\end{array}$ & $\begin{array}{c}\text { Mathematical } \\
\text { Value 1.17 }\left(\mathbf{R}_{1^{-}}-\right. \\
\left.\mathbf{R}_{2}\right) \mathbf{C}(\boldsymbol{\mu} \mathrm{s})\end{array}$ & $\begin{array}{l}\text { Simulated } \\
\text { Result }(\mu \mathrm{s})\end{array}$ & $\begin{array}{c}\text { Percentage } \\
\text { Resistance } \\
\text { variation }\end{array}$ \\
\hline 1 & 47 & 47 & 0 & 20 & 0 & 0 & 0 \\
\hline 2 & 47 & 48 & 1 & 20 & 23.4 & 22 & 1.67 \\
\hline 3 & 47 & 49 & 2 & 20 & 46.8 & 45 & 3.33 \\
\hline 4 & 47 & 50 & 3 & 20 & 70.2 & 67.5 & 5.00 \\
\hline 5 & 47 & 51 & 4 & 20 & 93.6 & 89 & 6.67 \\
\hline 6 & 47 & 52 & 5 & 20 & 117 & 110 & 8.33 \\
\hline 7 & 47 & 53 & 6 & 20 & 140.4 & 132.5 & 10.00 \\
\hline 8 & 47 & 54 & 7 & 20 & 163.8 & 155 & 11.67 \\
\hline 9 & 47 & 55 & 8 & 20 & 187.2 & 176 & 13.33 \\
\hline 10 & 47 & 56 & 9 & 20 & 210.6 & 197.5 & 15.00 \\
\hline 11 & 47 & 57 & 10 & 20 & 234 & 219.5 & 16.67 \\
\hline 12 & 47 & 58 & 11 & 20 & 257.4 & 241 & 18.33 \\
\hline 13 & 47 & 59 & 12 & 20 & 280.8 & 264 & 20.00 \\
\hline 14 & 47 & 60 & 13 & 20 & 304.2 & 285 & 21.67 \\
\hline 15 & 47 & 61 & 14 & 20 & 327.6 & 308.5 & 23.33 \\
\hline 16 & 47 & 62 & 15 & 20 & 351 & 329.5 & 25.00 \\
\hline 17 & 47 & 63 & 16 & 20 & 374.4 & 353 & 26.67 \\
\hline 18 & 47 & 64 & 17 & 20 & 397.8 & 372.5 & 28.33 \\
\hline 19 & 47 & 65 & 18 & 20 & 421.2 & 395 & 30.00 \\
\hline 20 & 47 & 66 & 19 & 20 & 444.6 & 417.5 & 31.67 \\
\hline 21 & 47 & 67 & 20 & 20 & 468 & 439 & 33.33 \\
\hline 22 & 47 & 68 & 21 & 20 & 491.4 & 462 & 35.00 \\
\hline 23 & 47 & 69 & 22 & 20 & 514.8 & 483 & 36.67 \\
\hline 24 & 47 & 70 & 23 & 20 & 538.2 & 508 & 38.33 \\
\hline 25 & 47 & 71 & 24 & 20 & 561.6 & 527 & 40.00 \\
\hline 26 & 47 & 72 & 25 & 20 & 585 & 545 & 41.67 \\
\hline 27 & 47 & 73 & 26 & 20 & 608.4 & 565 & 43.33 \\
\hline 28 & 47 & 74 & 27 & 20 & 631.8 & 592 & 45.00 \\
\hline 29 & 47 & 75 & 28 & 20 & 655.2 & 614 & 46.67 \\
\hline 30 & 47 & 76 & 29 & 20 & 678.6 & 637 & 48.33 \\
\hline 31 & 47 & 77 & 30 & 20 & 702 & 658 & 50.00 \\
\hline 32 & 47 & 78 & 31 & 20 & 725.4 & 680 & 51.67 \\
\hline 33 & 47 & 79 & 32 & 20 & 748.8 & 702 & 53.33 \\
\hline 34 & 47 & 80 & 33 & 20 & 772.2 & 723 & 55.00 \\
\hline 35 & 47 & 81 & 34 & 20 & 795.6 & 744 & 56.67 \\
\hline 36 & 47 & 82 & 35 & 20 & 819 & 763 & 58.33 \\
\hline 37 & 47 & 83 & 36 & 20 & 842.4 & 790 & 60.00 \\
\hline 38 & 47 & 84 & 37 & 20 & 865.8 & 812 & 61.67 \\
\hline 39 & 47 & 85 & 38 & 20 & 889.2 & 833 & 63.33 \\
\hline
\end{tabular}


IIUM Engineering Journal, Vol. 12, No. 6, 2011: Special Issue in Science and Ethics

Zeeshan et al.

\begin{tabular}{|c|c|c|c|c|c|c|c|}
\hline 40 & 47 & 86 & 39 & 20 & 912.6 & 857 & 878 \\
\hline 41 & 47 & 87 & 40 & 20 & 936 & 898 & 66.67 \\
\hline 42 & 47 & 88 & 41 & 20 & 959.4 & 920 & 68.33 \\
\hline 43 & 47 & 89 & 42 & 20 & 982.8 & 942 & 70.00 \\
\hline 44 & 47 & 90 & 43 & 20 & 1006.2 & 964 & 71.67 \\
\hline 45 & 47 & 91 & 44 & 20 & 1029.6 & 988 & 73.33 \\
\hline 46 & 47 & 92 & 45 & 20 & 1053 & 1004 & 76.00 \\
\hline 47 & 47 & 93 & 46 & 20 & 1076.4 & 1036 & 78.33 \\
\hline 48 & 47 & 94 & 47 & 20 & 1099.8 & 1052 & 80.00 \\
\hline 49 & 47 & 95 & 48 & 20 & 1123.2 & 1066 & 81.67 \\
\hline 50 & 47 & 96 & 49 & 20 & 1146.6 & 1100 & 83.33 \\
\hline 51 & 47 & 97 & 50 & 20 & 1170 & 1100 & 85.00 \\
\hline 52 & 47 & 98 & 51 & 20 & 1193.4 & 1130 & 86.67 \\
\hline 53 & 47 & 99 & 52 & 20 & 1216.8 & 1160 & 88.33 \\
\hline 54 & 47 & 100 & 53 & 20 & 1240.2 & & \\
\hline
\end{tabular}

Table 2.

\begin{tabular}{|c|c|c|c|c|c|c|c|}
\hline S.No & $\begin{array}{c}\mathbf{C}_{1} \\
(\mu \mathrm{F})\end{array}$ & $\begin{array}{c}\mathbf{C}_{2} \\
(\mu \mathbf{F})\end{array}$ & $\begin{array}{c}\text { Change } \\
\text { in } C(\mu F)\end{array}$ & $\begin{array}{c}\mathbf{R} \\
(\boldsymbol{\Omega})\end{array}$ & $\begin{array}{c}\text { Mathematical } \\
\text { Value } 1.17\left(\mathrm{C}_{2^{-}}\right. \\
\left.\mathrm{C}_{1}\right) \mathrm{R}(\boldsymbol{\mu} \mathrm{s})\end{array}$ & $\begin{array}{l}\text { Simulated } \\
\text { Result }(\mu \mathrm{s})\end{array}$ & $\begin{array}{c}\text { Percentage } \\
\text { capacitance } \\
\text { variation }\end{array}$ \\
\hline 1 & 10 & 10 & 0 & 10 & 0 & 0 & 0.00 \\
\hline 2 & 10 & 11 & 1 & 10 & 11.7 & 11.6 & 1.67 \\
\hline 3 & 10 & 12 & 2 & 10 & 23.4 & 22.2 & 3.33 \\
\hline 4 & 10 & 13 & 3 & 10 & 35.1 & 33.5 & 5.00 \\
\hline 5 & 10 & 14 & 4 & 10 & 46.8 & 44 & 6.67 \\
\hline 6 & 10 & 15 & 5 & 10 & 58.5 & 55.5 & 8.33 \\
\hline 7 & 10 & 16 & 6 & 10 & 70.2 & 66.4 & 10.00 \\
\hline 8 & 10 & 17 & 7 & 10 & 81.9 & 77.2 & 11.67 \\
\hline 9 & 10 & 18 & 8 & 10 & 93.6 & 87.4 & 13.33 \\
\hline 10 & 10 & 19 & 9 & 10 & 105.3 & 98.8 & 15.00 \\
\hline 11 & 10 & 20 & 10 & 10 & 117 & 109.6 & 16.67 \\
\hline 12 & 10 & 21 & 11 & 10 & 128.7 & 122 & 18.33 \\
\hline 13 & 10 & 22 & 12 & 10 & 140.4 & 132 & 20.00 \\
\hline 14 & 10 & 23 & 13 & 10 & 152.1 & 144 & 21.67 \\
\hline 15 & 10 & 24 & 14 & 10 & 163.8 & 155 & 23.33 \\
\hline 16 & 10 & 25 & 15 & 10 & 175.5 & 165 & 25.00 \\
\hline 17 & 10 & 26 & 16 & 10 & 187.2 & 175 & 26.67 \\
\hline 18 & 10 & 27 & 17 & 10 & 198.9 & 185 & 28.33 \\
\hline 19 & 10 & 28 & 18 & 10 & 210.6 & 195 & 30.00 \\
\hline 20 & 10 & 29 & 19 & 10 & 222.3 & 209 & 31.67 \\
\hline 21 & 10 & 30 & 20 & 10 & 234 & 219.5 & 33.33 \\
\hline 22 & 10 & 31 & 21 & 10 & 245.7 & 230 & 35.00 \\
\hline 23 & 10 & 32 & 22 & 10 & 257.4 & 240 & 36.67 \\
\hline
\end{tabular}


IIUM Engineering Journal, Vol. 12, No. 6, 2011: Special Issue in Science and Ethics

Zeeshan et al.

\begin{tabular}{|c|c|c|c|c|c|c|c|}
\hline 24 & 10 & 33 & 23 & 10 & 269.1 & 251 & 38.33 \\
\hline 25 & 10 & 34 & 24 & 10 & 280.8 & 261 & 40.00 \\
\hline 26 & 10 & 35 & 25 & 10 & 292.5 & 272.5 & 41.67 \\
\hline 27 & 10 & 36 & 26 & 10 & 304.2 & 282.5 & 43.33 \\
\hline 28 & 10 & 37 & 27 & 10 & 315.9 & 297.5 & 45.00 \\
\hline 29 & 10 & 38 & 28 & 10 & 327.6 & 306 & 46.67 \\
\hline 30 & 10 & 39 & 29 & 10 & 339.3 & 320 & 48.33 \\
\hline 31 & 10 & 40 & 30 & 10 & 351 & 330 & 50.00 \\
\hline 32 & 10 & 41 & 31 & 10 & 362.7 & 339.25 & 51.67 \\
\hline 33 & 10 & 42 & 32 & 10 & 374.4 & 350 & 53.33 \\
\hline 34 & 10 & 43 & 33 & 10 & 386.1 & 362 & 55.00 \\
\hline 35 & 10 & 44 & 34 & 10 & 397.8 & 372 & 56.67 \\
\hline 36 & 10 & 45 & 35 & 10 & 409.5 & 383 & 58.33 \\
\hline 37 & 10 & 46 & 36 & 10 & 421.2 & 395 & 60.00 \\
\hline 38 & 10 & 47 & 37 & 10 & 432.9 & 405 & 61.67 \\
\hline 39 & 10 & 48 & 38 & 10 & 444.6 & 418 & 63.33 \\
\hline 40 & 10 & 49 & 39 & 10 & 456.3 & 430 & 65.00 \\
\hline 41 & 10 & 50 & 40 & 10 & 468 & 440 & 66.67 \\
\hline 42 & 10 & 51 & 41 & 10 & 479.7 & 450 & 68.33 \\
\hline 43 & 10 & 52 & 42 & 10 & 491.4 & 460 & 70.00 \\
\hline 44 & 10 & 53 & 43 & 10 & 503.1 & 470 & 71.67 \\
\hline 45 & 10 & 54 & 44 & 10 & 514.8 & 480 & 73.33 \\
\hline 46 & 10 & 55 & 45 & 10 & 526.5 & 495 & 75.00 \\
\hline 47 & 10 & 56 & 46 & 10 & 538.2 & 504 & 76.67 \\
\hline 48 & 10 & 57 & 47 & 10 & 549.9 & 514 & 78.33 \\
\hline 49 & 10 & 58 & 48 & 10 & 561.6 & 524 & 80.00 \\
\hline 50 & 10 & 59 & 49 & 10 & 573.3 & 534 & 81.67 \\
\hline 51 & 10 & 60 & 50 & 10 & 585 & 547.44 & 83.33 \\
\hline 52 & 10 & 61 & 51 & 10 & 596.7 & 547.44 & 85.00 \\
\hline 53 & 10 & 62 & 52 & 10 & 608.4 & 547.44 & 86.67 \\
\hline 54 & 10 & 63 & 53 & 10 & 620.1 & 547.44 & 88.33 \\
\hline
\end{tabular}

